Research Article

\title{
Design, Characterization, and Application of The SCMNPs@PC/VB1-Zn as A Green and Recyclable Biocatalyst for Synthesis of Pyrano[2,3-c]pyrazole and 4H-benzo-[b]-pyran Derivatives
}

\author{
Fang Hou ${ }^{1, *}$, Wei Zheng1, Nasser Yousefi ${ }^{2}$ \\ ${ }^{1}$ Jiyuan Vocational and Technical College, Jiyuan, Henan 459000, China. \\ 2Islamic Azad University, Science and Research Branch, Tehran, Iran.
}

Received: 26 ${ }^{\text {th }}$ October 2019; Revised: $3^{\text {rd }}$ January 2020; Accepted: $3^{\text {rd }}$ January 2020; Available online: 28th February 2020; Published regularly: April 2020

\begin{abstract}
Eco-friendly and reusable solid acid catalysts (SCMNPs@PC/VB $1-Z n)$ were identified as one of the most effective basic catalysts for the composition of a pot, three-component pyrano[2,3-c]pyrazoles. Methyl-1phenyl-1H-pyrazole-5(4H)-one, benzaldehyde and malononitrile in high yield at $80{ }^{\circ} \mathrm{C}$. SCMNPs@ $\mathrm{PC} / \mathrm{VB}_{1}-\mathrm{Zn}$ reports the simple and efficient catalysis of a three-component pot reaction of dimedone, aldehydes, and malononitrile to $4 H$-benzo-[b]-pyran derivatives. This magnetic nanocatalyst can be recycled more than 6 times without dramatically reducing performance with respect to reaction time and efficiency. Copyright (C) 2020 BCREC Group. All rights reserved
\end{abstract}

Keywords: Recyclable biocatalyst; Magnetic nanocatalyst; Synthesis; Pyran derivatives; Eco-friendly

How to Cite: Hou, F., Wei Zheng, W., Yousefi, N. (2020). Design, Characterization and Application of The SCMNPs@PC/VB1-Zn as A Green and Recyclable Biocatalyst for Synthesis of Pyrano[2,3c]pyrazole and 4H-benzo-[b]-pyran Derivatives. Bulletin of Chemical Reaction Engineering \& Catalysis, 15(1), 199-212 (doi:10.9767/bcrec.15.1.6179.199-212)

Permalink/DOI: https://doi.org/10.9767/bcrec.15.1.6179.199-212

\section{Introduction}

Iron oxide magnetic nanoparticles, especially magnetite $\left(\mathrm{Fe}_{3} \mathrm{O}_{4}\right)$ as the most extensive investigated magnetic nanoparticles (MNPs), exhibit unique physical and chemical features compared to the bulk materials and their use is expanding quite rapidly. Various strategies have been used to prepare $\mathrm{Fe}_{3} \mathrm{O}_{4}$ core-shell nanocomposites including coprecipitation [1], thermal decomposition [2], ultrasound irradiation, microemulsion, and hydrothermal synthesis [3] of which thermal decomposition and coprecipitation are the most commonly used procedures. $\mathrm{Fe}_{3} \mathrm{O}_{4}$ MNPs are particularly promi-

* Corresponding Author.

Email: jyhoufang@163.com (F. Hou); nent due to their distinctive characteristics (e.g. high surface area, high pressure, low blindness temperature, high stability, superconductivity, and low toxicity [4-9]) in various applications including medical diagnosis, drug delivery, color imaging, cancer treatment, information storage, catalyst, microwave absorption, biosensors and organic and inorganic transformations [10-17]. The magnetic nature of these nanoparticles enables them to be easily separated from the reaction solution using an external magnetic field to eliminate the need for filtration and reuse several runs with a slight decrease in product yield and reaction time [18-21].

As remarkable compounds, the substituted pyrano[2,3-c]pyrazoles have achieved considerable interest over the past years due to their perfect range of pharmacological and biological ac- 
tivities, including the inhibitors of human Chk1 kinase [22], antimicrobial [23], antiinflammatory [24], and anticancer [25] activities. In one of the important ways, pyrano[2,3c]pyrazole derivatives were synthesized by the three-component condensation reaction of pyrazolone, malononitrile, and aldehyde in the presence of various catalysts, such as: $\mathrm{KF} \cdot 2 \mathrm{H}_{2} \mathrm{O}$ [26], $\mathrm{BF}_{3} / \mathrm{MNPs}$ [27], $p$-dodecylbenzene sulfonic acid (DBSA) [28], $\mathrm{H}_{14}\left[\mathrm{NaP}_{5} \mathrm{~W}_{30} \mathrm{O}_{110}\right]$ [29], triethylbenzylammonium chloride (TEBA) [30], $\mathrm{MgO}$ [31], and hexadecyltrimethylammonium bromide (HTMAB) [32]. Most of the procedures reported for the preparation of these kind of heterocyclic compounds are associated with demerits such as long reaction time, low yields, the use of hazardous organic solvents, lack of general applicability, tedious work-up methods, use of toxic catalysts, and harsh reaction conditions. Therefore, the introduction of new and efficient strategy for the synthesis of pyrano[2,3-c]pyrazole derivatives can be useful.

Over last decades, three-component one-pot condensation of dimedone, malononitrile, and aldehyde have been reported for the construction of substituted $4 H$-benzo-[b]-pyrans via several homogeneous and heterogeneous catalytic systems, such as: nanoparticles [33], microwave irradiation [34], ionic liquid [35], quaternary ammonium salt [36], TFE [37], TBAB [38], ultrasound irradiations [39], KF-alumina [40], rare earth perfluorooctanoate [41], IRA-400 $(\mathrm{OH}-)$ [42], DMF [43], DABCO [44], urea [45], Lproline [46], HDMBAB [47], potassium phosphate [48], TBAF [49], and molecular iodine [50]. Although most of these procedures offer distinct advantages, they may have some limitations such as low yield of the products, long reaction times, use of hazardous organic solvents, harsh reaction conditions, difficult work-

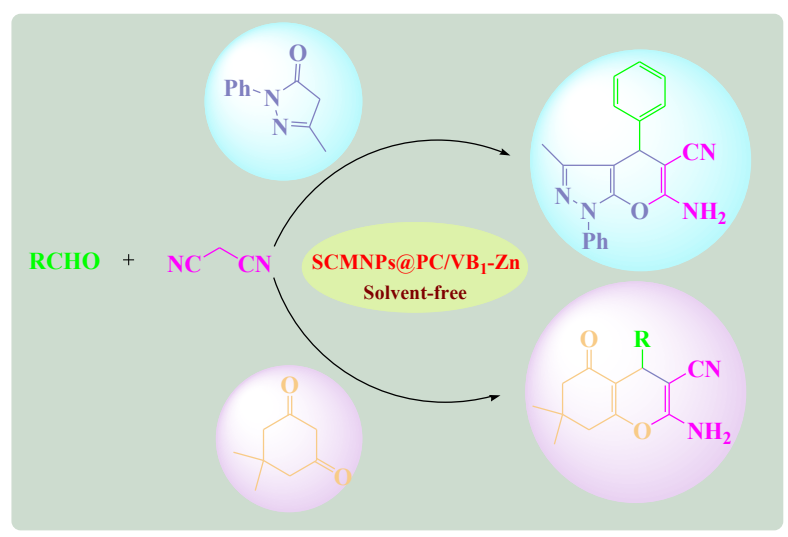

Scheme 1. Synthesis of pyrano[2,3-c]pyrazole and 4H-benzo-[b]-pyran derivatives using SCMNPs@PC/VB $1-Z n$. up, and use of toxic catalysts. Therefore, it is desirable to propose a new and efficient strategy for the preparation of the substituted $4 \mathrm{H}$ benzo-[b]-pyrans.

In this study, we reported our outcomes for the rapid and efficient preparation of pyrano[2,3-c]pyrazoles and $4 H$-benzo-[b]-pyran derivatives using $\mathrm{SCMNPs}_{\mathrm{N}} \mathrm{PC} / \mathrm{VB}_{1}-\mathrm{Zn}$ as a green and recyclable heterogeneous magnetic biocatalyst under solvent-free conditions (Scheme 1).

\section{Materials and Methods}

\subsection{Experimental}

FT-IR spectra were collected with a PerkinElmer PXI spectrometer in the range 400$4000 \mathrm{~cm}^{-1}$ on $\mathrm{KBr}$ pellets. The X-ray diffraction patterns of samples were obtained in the $2 \theta$ range of $10-80^{\circ}$ at room temperature on a Philips X-pert diffractometer (Holland) with Co-K $\alpha(\lambda=1.54 \AA)$. Scanning electron microphotograph (SEM) was utilized to survey the catalyst morphology on an LEO 1430VP instrument. Thermal gravimetric analysis was performed using a Linseis STA PT 1000 instrument with a heating rate of $10{ }^{\circ} \mathrm{C} / \mathrm{min}$ over a temperature range of $25-700{ }^{\circ} \mathrm{C}$ under $\mathrm{N}_{2}$ atmosphere. The magnetic susceptibility measurements of the catalyst were obtained using a vibrating sample magnetometry (VSM; Lake Shore 7200 at $300 \mathrm{kVsm}$ ).

\subsection{Catalyst Synthesis}

2.2.1 Preparation of the $\mathrm{Fe}_{3} \mathrm{O}_{4}$ magnetic nanoparticles $\left(\mathrm{Fe}_{3} \mathrm{O}_{4} \mathrm{MNPs}\right.$ )

First, a mixture of $4.8 \mathrm{~g} \mathrm{FeCl}_{3} .6 \mathrm{H}_{2} \mathrm{O}$ and 2.4 g $\mathrm{FeCl}_{2} .4 \mathrm{H}_{2} \mathrm{O}$ was added to $100 \mathrm{~mL}$ of deionized water and the contents of the reaction vessel were vigorously stirred under the argon atmosphere at $80^{\circ} \mathrm{C}$ for $20 \mathrm{~min}$. Then, $10 \mathrm{~mL}$ of concentrated solution of ammonia was added quickly to the reaction solution and stirred again for $30 \mathrm{~min}$. To achieve the desired precursor, the reaction solution was cooled and the formed black magnetic nanoparticles were isolated by the magnetic decantation. The desired precipitates were consecutively washed with deionized water and dried overnight in the absence of temperature under vacuum.

\subsubsection{Preparation of the silica-coated magnetic} nanoparticles (SCMNPs)

First, the achieved black magnetic nanoparticles from the first step was dispersed in a mixture of ethanol $(80 \mathrm{~mL})$, deionized water 
(25 $\mathrm{mL}$ ) and concentrated aqueous ammonia (8 $\mathrm{mL}$ ) and was sonicated for $30 \mathrm{~min}$. Under continuous mechanical stirring, $20 \mathrm{~mL}$ of tetraethylorthosilicate (TEOS) was added to the reaction solution and was stirred for $24 \mathrm{~h}$. The obtained $\mathrm{Fe}_{3} \mathrm{O}_{4} @ \mathrm{SiO}_{2}$ precipitate was separated by magnetic decantation and consecutively washed with deionized water and ethanol and dried under vacuum at $50{ }^{\circ} \mathrm{C}$ for $10 \mathrm{~h}$.

2.2.3 Preparation of the silica-coated magnetic nanoparticles bonded 3-

chloropropyltriethoxysilane (SCMNPs@PC)

The $4 \mathrm{~mL}$ of 3-chloropropyltriethoxysilane (CPTCSi) was added to the reaction vessel containing $2 \mathrm{~g}$ of dispersed $\mathrm{SC} @ \mathrm{Fe}_{3} \mathrm{O}_{4} \mathrm{MNPs}$ in $50 \mathrm{~mL}$ dry toluene and stirred at $60{ }^{\circ} \mathrm{C}$ for $24 \mathrm{~h}$. The residue solid (SCMNPs@PC) was separated via the magnetic decantation, consecutively washed with ethanol to remove the excess CPTCSi, and dried in a vacuum oven at $60{ }^{\circ} \mathrm{C}$ for $12 \mathrm{~h}$.

\subsubsection{Preparation of the SCMNPs@PC/VB 1}

The $2 \mathrm{~g}$ of SCMNPs@PC was added to the reaction vessel containing $50 \mathrm{~mL}$ of ethanol and dispersed for $30 \mathrm{~min}$. Then, $1 \mathrm{mmol}$ of thiamine hydrochloride $\left(\mathrm{VB}_{1}\right)$ and 3-4 drop of triethylamine were added to the reaction mixture and refluxed for $12 \mathrm{~h}$. The solid residue was extracted by an appropriate magnetic field, consecutively washed with ethanol, and dried under the vacuum oven.

\subsubsection{Preparation of SCMNPs@PC/VB $1-\mathrm{Zn}$.}

The $2 \mathrm{~g}$ of the prepared SCMNPs@PC/VB 1 was dispersed in $50 \mathrm{~mL}$ of acetonitrile for 30 min. Then, $0.1 \mathrm{~g}$ of $\mathrm{Zn}(\mathrm{OAc})_{2}$ was poured to the reaction solution. After that, the contents of the reaction vessel were refluxed for $24 \mathrm{~h}$ and the

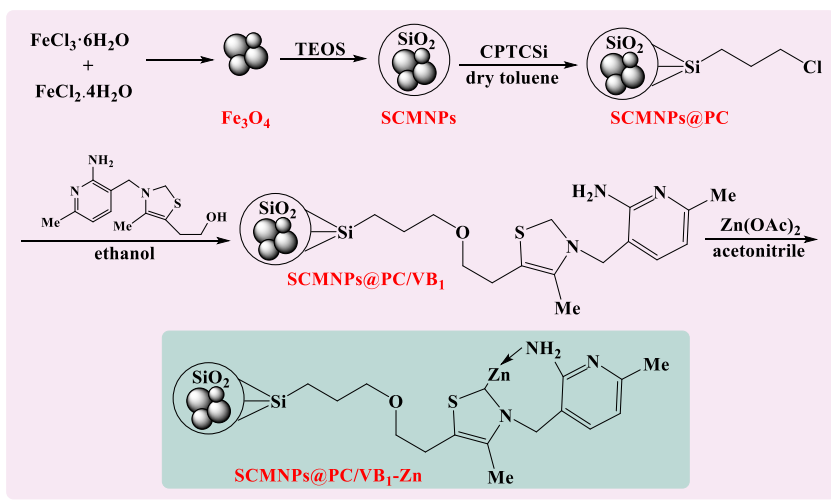

Scheme 2. Preparation of SCMNPs@PC/VB $1-Z n$ core-shell catalyst. resulting nanoparticles were isolated using an external magnetic field. The solid residue was washed several times with dry ethanol and dried at $70{ }^{\circ} \mathrm{C}$ for $24 \mathrm{~h}$. All stages of the SCMNPs@PC/VB $1-Z n$ synthesis are shown in Scheme 2.

2.2.6 Typical procedure for the preparation of $4 H$-benzo-[b]-pyran derivatives.

A mixture of 3-methyl-1-phenyl-1H-pyrazol5(4H)-one (1 mmol), aldehyde (1.1 $\mathrm{mmol})$, malononitrile (1.1 $\mathrm{mmol})$, and SCMNPs@PC/VB 1 -Zn (10 mg) was stirred at 80 ${ }^{\circ} \mathrm{C}$ in the absence of any solvents for the appropriate time. The progress of the reaction was monitored by thin layer chromatography (TLC). In order to extraction of the catalyst, ethanol was added to the reaction vessel and stirred at $70{ }^{\circ} \mathrm{C}$. After complete dissolution of the product in the desired solvent, the catalyst was isolated from reaction solution by an external magnetic field and rinsed several times with ethanol. The obtained products were crystallized from ethanol to give pure products.

2.2.7 Typical procedure for the preparation of pyrano[2,3-c]pyrazole derivatives.

A mixture of dimedone (1 $\mathrm{mmol})$, aldehyde (1 mmol), malononitrile (1.2 mmol), and SCMNPs@PC/VB 1 -Zn (10 mg) was stirred at 50 ${ }^{\circ} \mathrm{C}$ in the absence of any solvents for the appropriate time. After completion of the reaction, as it can be seen from thin layer chromatography (TLC), ethanol was added to the reaction vessel and stirred at $70{ }^{\circ} \mathrm{C}$. After complete dissolution of the product in the desired solvent, the catalyst was isolated from reaction mixture by an external magnetic field and rinsed several times with ethanol. After evaporation of ethanol, the achieved products were washed with nhexane to give appropriate compound in pure form.

\section{Results and Discussion}

\subsection{FTIR Analysis of SCMNPs@PC/VB $1-Z n$}

Figure 1 shows the FT-IR spectra of $\mathrm{Fe}_{3} \mathrm{O}_{4}$ MNPs, SCMNPs, SCMNPs@PC, SCMNPs@PC/VB 1 , and SCMNPs@PC/VB $1-Z n$. As is clear from all of the spectra, the broad absorption of $3408 \mathrm{~cm}^{-1}$ belongs to the $\mathrm{O}-\mathrm{H}$ stretching vibrations. In the spectrum of $\mathrm{Fe}_{3} \mathrm{O}_{4}$ MNPs, the characteristic absorption at 585 and $456 \mathrm{~cm}^{-1}$ are associated to Fe-O-Fe stretching vibrations related to the magnetite phase. As can be seen from the FT-IR spectrum of the SCMNPs, the introduction of a layer of $\mathrm{SiO}_{2}$ to 
the surface of MNPs can be verified by band at $1103 \mathrm{~cm}^{-1}$ which is assigned to the stretching vibration of Si-O-Si group. After bonding the SCMNPs with 3-chloropropyltriethoxysilane (CPTCSi), the FT-IR spectrum of the SCMNPs@PC exhibits a new peak at $2985 \mathrm{~cm}^{-1}$ assigned to the $\mathrm{C}-\mathrm{H}$ stretching vibration of the aliphatic group. The bands at 1533 and 1640 $\mathrm{cm}^{-1}$ are attributable to the $\mathrm{C}-\mathrm{N}$ and $\mathrm{N}-\mathrm{H}\left(\mathrm{NH}_{2}\right)$ vibrations of the $\mathrm{VB}_{1}$ group indicate that the SCMNPs@PC are functionalized with thiamine. It should be noted that the $\mathrm{C}-\mathrm{N}$ and $\mathrm{N}-\mathrm{H}$ signal of the SCMNPs@PC/VB $1-\mathrm{Zn}$ are shifted to a lower wavenumber than the C-N and N-H signal of the SCMNPs@PC/VB 1 (1529 and 1637 $\mathrm{cm}^{-1}$ rather than 1533 and $\left.1640 \mathrm{~cm}^{-1}\right)$.

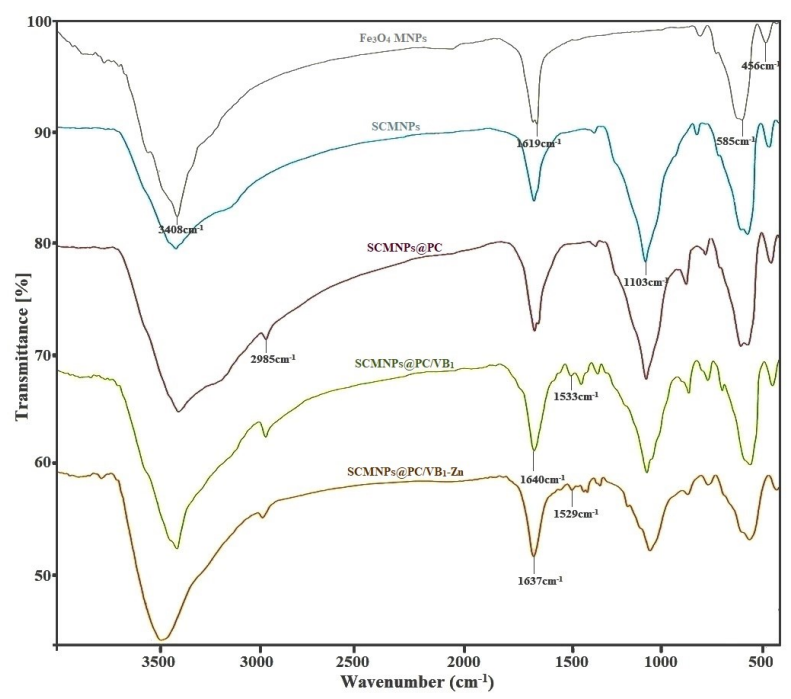

Figure 1. The FT-IR spectra of $\mathrm{Fe}_{3} \mathrm{O}_{4} \mathrm{MNPs}$, SCMNPs, SCMNPs@PC, SCMNPs@PC/VB and SCMNPs@PC/VB $1-Z n$.

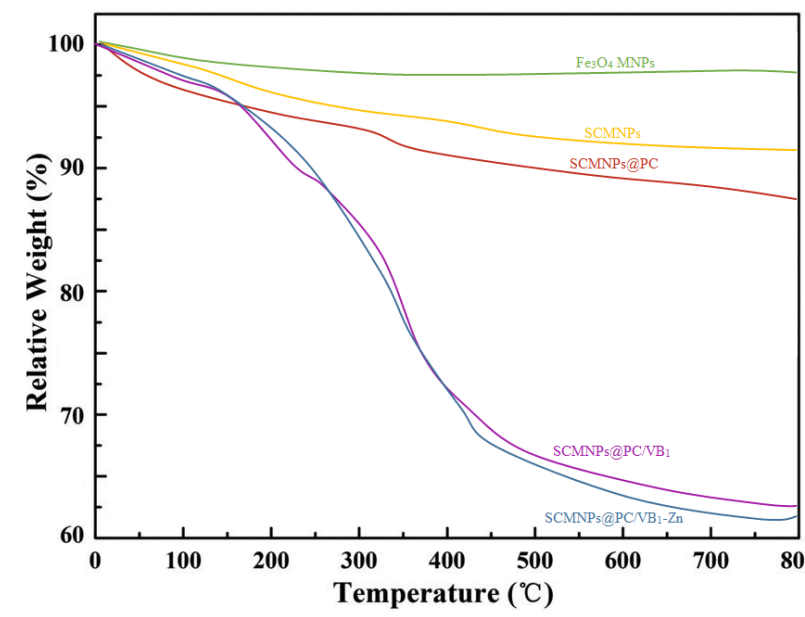

Figure 2. The TGA diagrams of $\mathrm{Fe}_{3} \mathrm{O}_{4} \mathrm{MNPs}$, SCMNPs, $\quad$ SCMNPs@PC, SCMNPs@PC/VB 1 , and SCMNPs@PC/VB $1-Z n$.

\subsection{TGA Analysis of SCMNPs@PC/VB $1-Z n$.}

Using TGA, we investigated the thermal stability of the $\mathrm{Fe}_{3} \mathrm{O}_{4}$ MNPs, SCMNPs, SCMNPs@PC, SCMNPs@PC/VB 1 , and $\mathrm{SCMNPs} @ \mathrm{PC} / \mathrm{VB}_{1}-\mathrm{Zn}$ were investigated. The outcomes of these analyses are exhibited in Figure 2. In the TGA curve of the all samples, the first small amount of weight loss in 100$150{ }^{\circ} \mathrm{C}$ is attributed to the both the physisorbed and chemisorbed solvents and hydroxyl groups on the surface of the magnetic nanoparticles. In the TGA curve of SCMNPs@PC, a weight loss below $350{ }^{\circ} \mathrm{C}$ is resulted from the decomposition of the coating organic layer of chloropropyl on the $\mathrm{Fe}_{3} \mathrm{O}_{4} \mathrm{MNPs}$ surface. The weight loss of the SCMNPs@PC/VB 1 , and SCMNPs@PC/VB $1-\mathrm{Zn}$ at the temperature range of $150-450^{\circ} \mathrm{C}$ are attributed to the decomposition of the organic parts of chloropropyl and thiamine on the surface of the magnetic phase.

\subsection{EDX analysis of SCMNPs@PC/VB $1-\mathrm{Zn}$}

The results of the element distribution of SCMNPs@PC/VB 1 -Zn were further surveyed by EDX analysis (Figure 3). The coating of $\mathrm{SiO}_{2}$ on the $\mathrm{Fe}_{3} \mathrm{O}_{4}$ MNPs surface was verified by the presence of $\mathrm{Si}, \mathrm{Fe}$, and $\mathrm{O}$ signals. The existence of $\mathrm{C}, \mathrm{S}, \mathrm{O}$, and $\mathrm{N}$ signals exhibits that the thiamine is loaded on the surface of SCMNPs@PC/VB 1 . The EDX analysis also presents the existence of the zinc element indicating coordination of $\mathrm{Zn}$ with thiamine. The appearance of the zinc element in the EDX analysis is attributed to SCMNPs@PC/VB 1 -Zn catalyst, indicating coordination of $\mathrm{Zn}$ with thiamine has been done successfully.

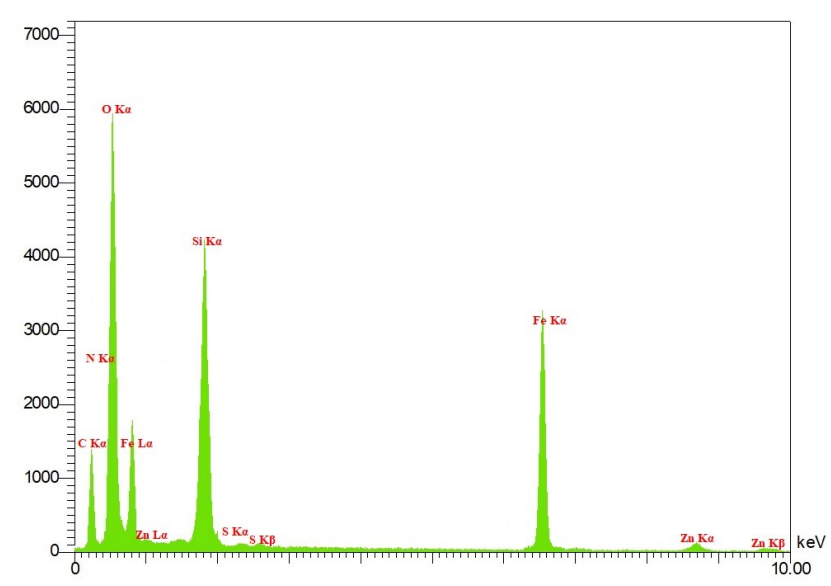

Figure 3. EDX image of SCMNPs@PC/VB $1-Z n$. 


\subsection{VSM Analysis of SCMNPs@PC/VB $1-\mathrm{Zn}$}

The magnetization curves of $\mathrm{Fe}_{3} \mathrm{O}_{4} \mathrm{MNPS}$ and SCMNPs@PC/VB 1 -Zn catalyst were investigated by vibrating sample magnetometry at room temperature (Figure 4 ). The curves show a decrease in the saturation magnetization (Ms) values from $61.38 \mathrm{emu} / \mathrm{g}\left(\mathrm{Fe}_{3} \mathrm{O}_{4} \mathrm{MNPs}\right)$ to $37.45 \mathrm{emu} / \mathrm{g}$ (SCMNPs@PC/VB $1-\mathrm{Zn})$ due to the successful grafting of non-magnetic silica layer and other functional groups (chloropropyl, thiamine- $\mathrm{Zn}$ ) on the surface of $\mathrm{Fe}_{3} \mathrm{O}_{4}$ MNPs. Although the values of the catalyst saturation magnetization have decreased sequentially due to the magnetic nature of the SCMNPs@PC/VB $1-Z n$, the achieved heterogeneous magnetic nanocatalyst can be separated from the reaction solution via an external mag-

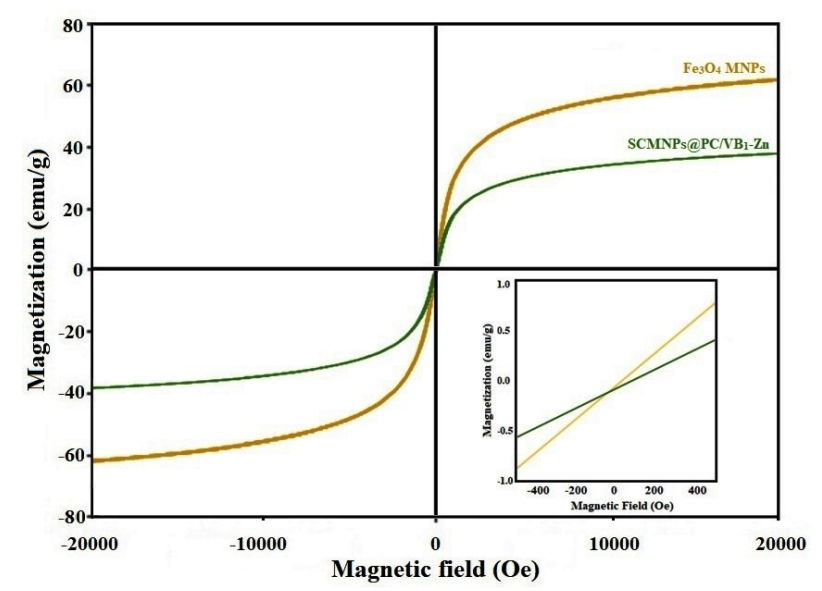

Figure 4. VSM analysis of SCMNPs@PC/ $\mathrm{VB}_{1}-\mathrm{Zn}$.



Figure 6. SEM pattern of SCMNPs@PC/VB 1 $\mathrm{Zn}$ (A) and recovered SCMNPs@PC/VB $-\mathrm{Zn}$ (B). netic field.

\subsection{XRD Analysis of SCMNPs@PC/VB $1-Z n$.}

As shown in Figure 5, the X-ray diffraction (XRD) spectrum of the $\mathrm{Fe}_{3} \mathrm{O}_{4}$ MNPs, and SCMNPs@PC/VB $1-Z n$ was recognized by six characteristic peak positions at $2 \theta=30.78$, $36.84,47.56,56.85,62.92$, and 68.54 were indexed to the (220), (311), (400), (422), (511), and (440) planes, respectively, which are appropriately in line with the crystalline cubic spinel structure (JCPDS card no. 19-0629) of $\mathrm{Fe}_{3} \mathrm{O}_{4}$ magnetic nanoparticles. It has been verified that the surface modification of the $\mathrm{Fe}_{3} \mathrm{O}_{4}$ magnetic nanoparticles has not changed during the grafting of silica layer and other functional groups (chloropropyl, thiamine-Zn).

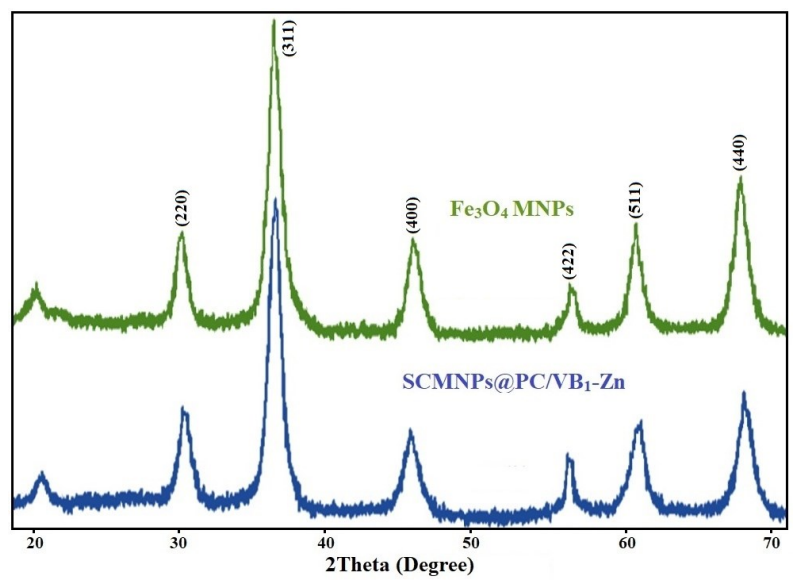

Figure 5. XRD pattern of $\mathrm{Fe}_{3} \mathrm{O}_{4}$ MNPs and SCMNPs@PC/VB $1-Z n$.

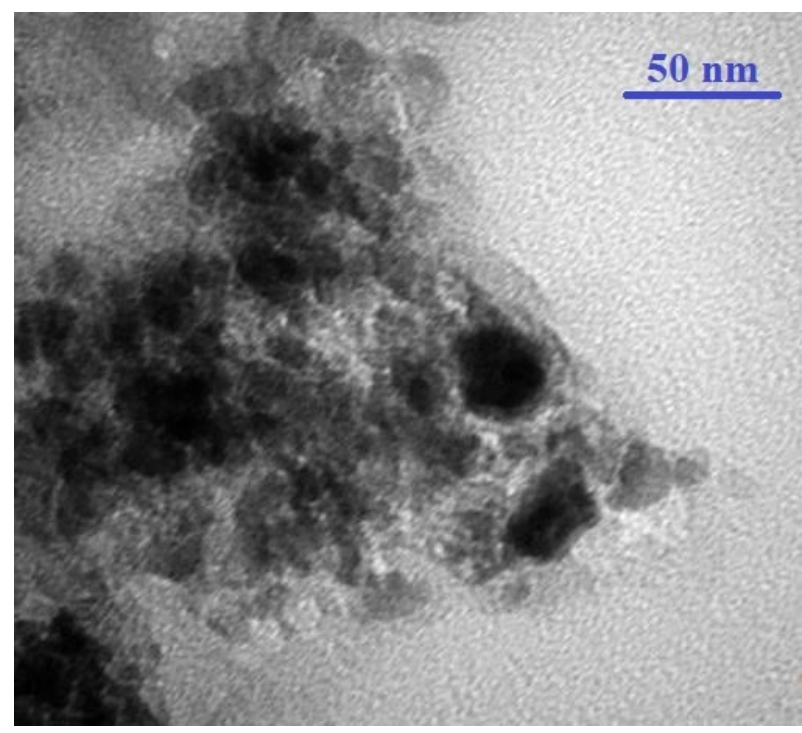

Figure 7. TEM image of SCMNPs@PC/VB ${ }_{1}^{-}$ Zn. 


\subsection{SEM Analysis of SCMNPs@PC/VB $1-\mathrm{Zn}$}

As shown in Figure 6, in order to determine the variations in the surface of the prepared magnetic nanoparticles, the morphology and size of the $\mathrm{SCMNPs} @ \mathrm{PC} / \mathrm{VB}_{1}-\mathrm{Zn}(\mathrm{A})$ and recovered SCMNPs@PC/VB 1 -Zn (B) were studied by scanning electron microscopy (SEM). The SCMNPs@PC/VB 1 -Zn (A) exhibits a nearly spherical structure with an average particle diameter about $32 \mathrm{~nm}$. As is clear from SEM images, the diameters of the recovered SCMNPs@PC/VB 1 -Zn (B) are about 38-46 nm with a negligible increase in the size.

\subsection{TEM Analysis of SCMNPs@PC/VB 1 -Zn}

The TEM image of the SCMNPs@PC/VB ${ }_{1}$ $\mathrm{Zn}$ exhibits that the dark $\mathrm{Fe}_{3} \mathrm{O}_{4}$ MNPs cores have an almost spherical shape with a narrow size distribution and surrounded by the grey silica shell (the average particle size is $50 \mathrm{~nm}$, Figure 7). In the first study, the condensation of 3-methyl-1-phenyl-1H-pyrazol-5(4H)-one (1 $\mathrm{mmol})$, benzaldehyde $(1.1 \mathrm{mmol})$, and malononitrile $(1.1 \mathrm{mmol})$ for the synthesis of pyrano[2,3-c]pyrazoles was selected as a model reaction. The effects of amounts of SCMNPs@PC $/ \mathrm{VB}_{1}-\mathrm{Zn}$, reaction temperature, different sol-

Table 1. Optimization of the three-component reaction of 3-methyl-1-phenyl-1H-pyrazol-5(4H)-one, benzaldehyde, and malononitrile under various conditions ${ }^{\text {a }}$.

\begin{tabular}{|c|c|c|c|c|c|c|}
\hline & & $2 \mathrm{a}$ & & 4a & & \\
\hline Entry & Solvent & Catalyst (mg) & Temp. & $\begin{array}{l}\text { Time } \\
(\mathrm{min})\end{array}$ & $\begin{array}{c}\text { Yield } \\
(\%)^{b}\end{array}$ & Ref. \\
\hline 1 & $\mathrm{H}_{2} \mathrm{O}$ & $\mathrm{SCMNPs@PC/VB} B_{1}-\mathrm{Zn} / 10$ & Reflux & 65 & 80 & This work \\
\hline 2 & $\mathrm{EtOH}$ & $\mathrm{SCMNPs@PC/VB} B_{1}-\mathrm{Zn} / 10$ & Reflux & 30 & 89 & This work \\
\hline 3 & $\mathrm{MeOH}$ & $\mathrm{SCMNPs} @ \mathrm{PC} / \mathrm{VB}_{1}-\mathrm{Zn} / 10$ & Reflux & 35 & 87 & This work \\
\hline 4 & $\mathrm{CHCl}_{3}$ & SCMNPs@PC/VB $1-Z n / 10$ & Reflux & 90 & 82 & This work \\
\hline 5 & $\mathrm{CH}_{2} \mathrm{Cl}_{2}$ & SCMNPs@PC/VB $1-Z n / 10$ & Reflux & 150 & 79 & This work \\
\hline 6 & $\mathrm{CH}_{3} \mathrm{CN}$ & $\mathrm{SCMNPs@PC/VB} B_{1}-\mathrm{Zn} / 10$ & Reflux & 35 & 86 & This work \\
\hline 7 & Solvent- free & SCMNPs@PC/VB $1-Z n / 10$ & $80{ }^{\circ} \mathrm{C}$ & 15 & 96 & This work \\
\hline 8 & Solvent- free & $\mathrm{SCMNPs@PC/VB} 1-Z n / 10$ & $25^{\circ} \mathrm{C}$ & 70 & 52 & This work \\
\hline 9 & Solvent- free & $\mathrm{SCMNPs@PC/VB} B_{1}-\mathrm{Zn} / 10$ & $60^{\circ} \mathrm{C}$ & 30 & 85 & This work \\
\hline 10 & Solvent- free & SCMNPs@PC/VB $1-Z n / 10$ & $70{ }^{\circ} \mathrm{C}$ & 20 & 91 & This work \\
\hline 11 & Solvent- free & $\mathrm{SCMNPs} @ \mathrm{PC} / \mathrm{VB}_{1}-\mathrm{Zn} / 10$ & $90{ }^{\circ} \mathrm{C}$ & 15 & 95 & This work \\
\hline 12 & Solvent- free & SCMNPs@PC/VB $1-Z n / 10$ & $100^{\circ} \mathrm{C}$ & 15 & 93 & This work \\
\hline 13 & Solvent- free & SCMNPs@PC/VB $1-Z n / 15$ & $80^{\circ} \mathrm{C}$ & 15 & 94 & This work \\
\hline 14 & Solvent- free & $\mathrm{SCMNPs@PC/VB} 1-\mathrm{Zn} / 5$ & $80{ }^{\circ} \mathrm{C}$ & 35 & 75 & This work \\
\hline 15 & $\mathrm{H}_{2} \mathrm{O}$ & DBSA & $60{ }^{\circ} \mathrm{C}$ & 180 & 88 & [28] \\
\hline 16 & $\mathrm{EtOH}$ & $\mathrm{NH}_{4} \mathrm{H}_{2} \mathrm{PO}_{4} / \mathrm{Al}_{2} \mathrm{O}_{3}$ & Reflux & 15 & 84 & {$[51]$} \\
\hline 17 & $\mathrm{EtOH}$ & Sulfamic acid & Reflux & 600 & 82 & {$[52]$} \\
\hline 18 & $\mathrm{H}_{2} \mathrm{O}$ & НТМАВ & $85^{\circ} \mathrm{C}$ & 180 & 89 & {$[32]$} \\
\hline 19 & $\mathrm{H}_{2} \mathrm{O}$ & TEBA & $90{ }^{\circ} \mathrm{C}$ & 360 & 99 & [30] \\
\hline \multicolumn{7}{|c|}{$\begin{array}{l}\text { a Reaction conditions: } 3 \text {-methyl-1-phenyl-1H-pyrazol-5 }(4 H) \text {-one }(1 \mathrm{mmol}) \text {, benzaldehyde }(1.1 \mathrm{mmol}) \text {, malononitrile }(1.1 \mathrm{mmol}) \\
\text { and required amount of the catalyst. } \\
\text { b The yields refer to the isolated product. }\end{array}$} \\
\hline \multicolumn{7}{|c|}{ 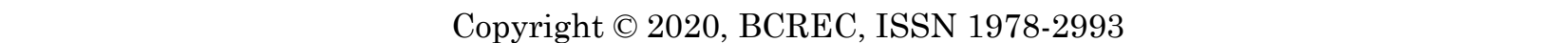 } \\
\hline
\end{tabular}


Table 2 SCMNPs@PC/VB 1 -Zn -Catalyzed synthesis of pyrano[2,3-c]pyrazole derivatives ${ }^{a}$

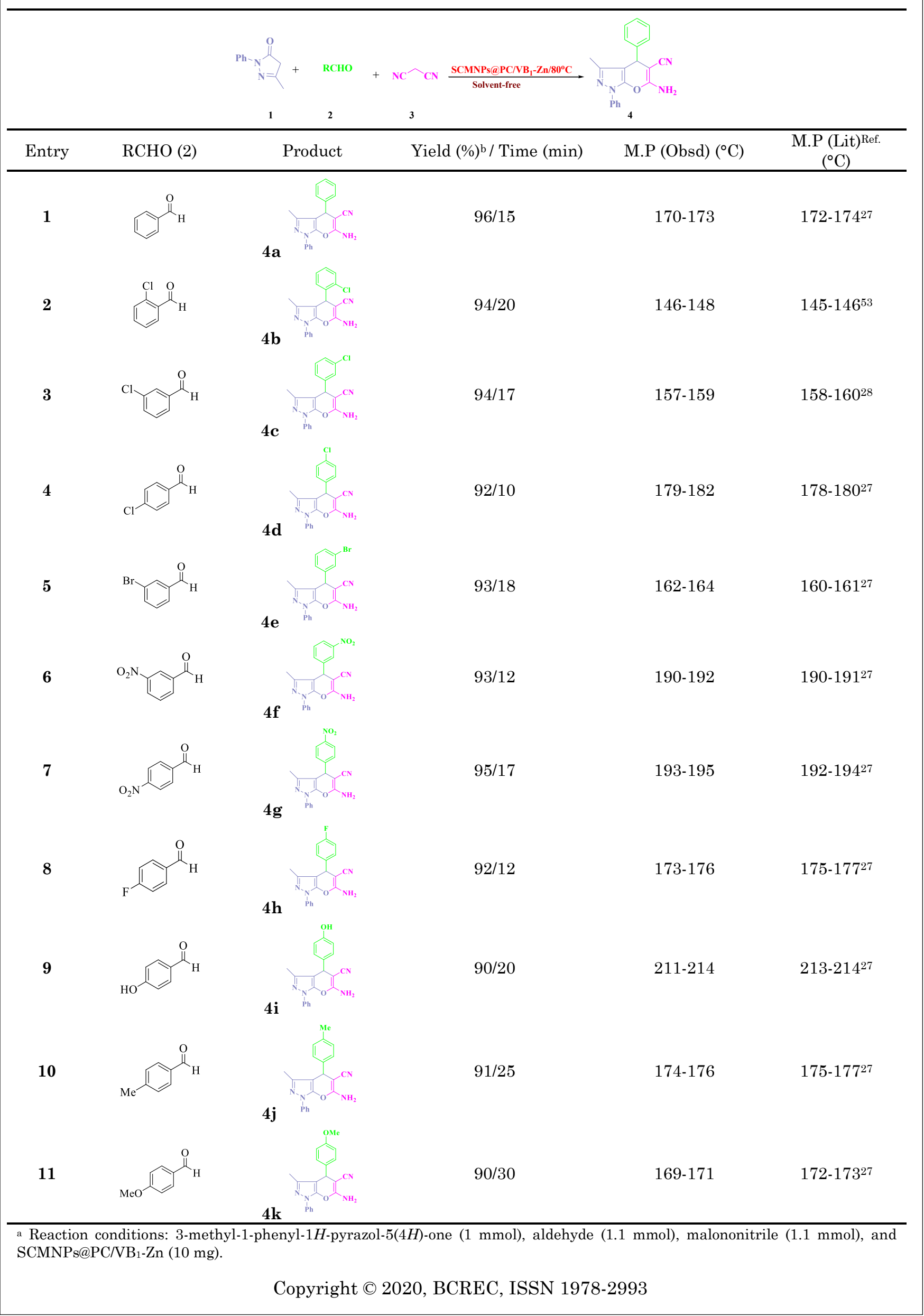


vents and solvent-free conditions were surveyed to optimize the reaction conditions. To study the role of solvent, the model reaction was carried out under different solvents such as $\mathrm{CHCl}_{3}, \mathrm{CH}_{2} \mathrm{Cl}_{2}, \mathrm{CH}_{3} \mathrm{CN}$, EtOH, $\mathrm{MeOH}$, and $\mathrm{H}_{2} \mathrm{O}$. The best catalytic activity of SCMNPs@PC/VB 1 -Zn was obtained in the absence of solvent (Table 1, Entry 7. Also, the SCMNPs@PC/VB $1-Z n$ catalyst in ethanol played a very important role in catalyzing the reaction (Table 1, Entry 2). To evaluate the appropriate concentration of catalyst, the model reaction was performed in the presence of 5,10 and 15 of SCMNPs@PC/VB 1 -Zn (Table 1, Entries 7 and 13-14). In this reaction, the best results were achieved using $10 \mathrm{mg}$ of catalyst (Table 1, Entry 7), while enhancing the amount of the catalyst did not affect the reaction times and yields (Table 1, Entry 13). When the model reaction was accomplished in the presence of 5 $\mathrm{mg}$ of catalyst under the optimized conditions for 35 minutes, the yield of the product was moderate (Table 1, Entry 14). To study the effect of temperature on this synthesis, the reaction was performed at $25,60,70,80,90$, and $100{ }^{\circ} \mathrm{C}$ in the presence of $10 \mathrm{mg}$ of SCMNPs@PC/VB 1 -Zn catalyst under solventfree conditions (Table 1, Entries 7-12). It was observed that the product yield was maximized at $80{ }^{\circ} \mathrm{C}$ (Table 1, Entry 7). To show the advantages of the our work in comparison with the other reported catalysts in the literature, we summarized some of the results for the preparation of pyrano[2,3-c]pyrazoles in this table (Table 1, Entries 15-19). The results showed that SCMNPs@PC/VB 1 -Zn is a more efficient catalyst than the reported ones in the literature with respect to the easy work-up, using a reusable catalyst, low catalyst loading, short reaction time and high yield.

To ascertain the scope and generality of the present system, various aromatic aldehydes

Table 3. Optimization of the three-component reaction of dimedone, 4-chlorobenzaldehyde, and malononitrile under various conditions ${ }^{\text {a }}$

\begin{tabular}{|c|c|c|c|c|c|c|}
\hline & & 2d & & & & \\
\hline Entry & Solvent & Catalyst (mg) & Temp. & $\begin{array}{l}\text { Time } \\
(\mathrm{min})\end{array}$ & $\begin{array}{c}\text { Yield } \\
(\%)^{\mathrm{b}}\end{array}$ & Ref \\
\hline 1 & $\mathrm{H}_{2} \mathrm{O}$ & SCMNPs@PC/VB $1-Z n / 10$ & Reflux & 10 & 89 & This work \\
\hline 2 & $\mathrm{EtOH}$ & $\mathrm{SCMNPs@PC/VB} 1-\mathrm{Zn} / 10$ & Reflux & 15 & 86 & This work \\
\hline 3 & $\mathrm{H}_{2} \mathrm{O}$-EtOH & SCMNPs@PC/VB $1-Z n / 10$ & Reflux & 10 & 92 & This work \\
\hline 4 & Solvent- free & SCMNPs@PC/VB $1-Z n / 10$ & $50{ }^{\circ} \mathrm{C}$ & 6 & 97 & This work \\
\hline 5 & Solvent- free & $\mathrm{SCMNPs@PC/VB} 1-Z n / 10$ & $25^{\circ} \mathrm{C}$ & 15 & 85 & This work \\
\hline 6 & Solvent- free & $\mathrm{SCMNPs@PC/VB} 1-\mathrm{Zn} / 10$ & $40^{\circ} \mathrm{C}$ & 10 & 92 & This work \\
\hline 7 & Solvent- free & $\mathrm{SCMNPs@PC/VB} 1-\mathrm{Zn} / 10$ & $60^{\circ} \mathrm{C}$ & 10 & 95 & This work \\
\hline 8 & Solvent- free & $\mathrm{SCMNPs}_{\mathrm{s}} \mathrm{PC} / \mathrm{VB}_{1}-\mathrm{Zn} / 10$ & $70{ }^{\circ} \mathrm{C}$ & 10 & 93 & This work \\
\hline 9 & Solvent- free & SCMNPs@PC/VB $1-Z n / 10$ & $80{ }^{\circ} \mathrm{C}$ & 10 & 91 & This work \\
\hline 10 & Solvent- free & SCMNPs@PC/VB $1-Z n / 15$ & $50{ }^{\circ} \mathrm{C}$ & 6 & 96 & This work \\
\hline 11 & Solvent- free & $\mathrm{SCMNPs@PC/VB} 1-\mathrm{Zn} / 5$ & $50^{\circ} \mathrm{C}$ & 15 & 83 & This work \\
\hline 12 & $\mathrm{H}_{2} \mathrm{O}$ & TBAB & Reflux & 40 & 90 & {$[54]$} \\
\hline 13 & $\mathrm{EtOH}$ & $\mathrm{RE}(\mathrm{PFO})_{3}$ & $60{ }^{\circ} \mathrm{C}$ & $4 \mathrm{~h}$ & 83 & [55] \\
\hline 14 & $\mathrm{H}_{2} \mathrm{O}$ & POPINO & Reflux & 10 & 92 & [56] \\
\hline 15 & $\mathrm{H}_{2} \mathrm{O}$-EtOH & $\mathrm{Na}_{2} \mathrm{SeO}_{4}$ & Reflux & $2.5 \mathrm{~h}$ & 90 & [57] \\
\hline 16 & $\mathrm{H}_{2} \mathrm{O}$ & $\mathrm{AP}-\mathrm{SiO}_{2}$ & $70^{\circ} \mathrm{C}$ & 60 & 92 & {$[58]$} \\
\hline \multicolumn{7}{|c|}{$\begin{array}{l}\text { a Reaction conditions: dimedone }(1 \mathrm{mmol}), 4 \text {-chlorobenzaldehyde }(1 \mathrm{mmol}) \text {, malononitrile }(1.2 \mathrm{mmol}) \text {, and required amount of the } \\
\text { catalysts. } \\
\text { b The yields refer to the isolated product. }\end{array}$} \\
\hline \multicolumn{7}{|c|}{ Copyright $@ 2020$, BCREC, ISSN 1978-2993 } \\
\hline
\end{tabular}


Table 4. SCMNPs@PC/VB1-Zn -Catalyzed synthesis of $4 H$-benzo-[b]-pyran derivatives a

\begin{tabular}{|c|c|c|c|c|c|}
\hline & & 2 & 3 & & \\
\hline$\overline{\text { Entry }}$ & RCHO (2) & Product & Yield $(\%)^{\mathrm{b}} /$ Time (min) & M.P(Obsd) $\left({ }^{\circ} \mathrm{C}\right)$ & $\begin{array}{c}\text { M.P (Lit)Ref } \\
\left({ }^{\circ} \mathrm{C}\right)\end{array}$ \\
\hline 1 & & & $94 / 8$ & $226-228$ & $227-229^{54}$ \\
\hline 2 & & & $97 / 5$ & $190-193$ & $191-192^{49}$ \\
\hline 3 & & & $92 / 6$ & $227-230$ & $228-229^{59}$ \\
\hline 4 & & & $97 / 6$ & $211-213$ & $212-214^{54}$ \\
\hline 5 & & & $98 / 6$ & $181-184$ & $182-183^{54}$ \\
\hline 6 & & & $95 / 7$ & $229-232$ & $230^{57}$ \\
\hline 7 & & & $96 / 6$ & 209-211 & $210-212^{54}$ \\
\hline 8 & & & $97 / 6$ & 179-182 & $178-180^{54}$ \\
\hline 9 & & & $97 / 7$ & 209-212 & $210-211^{49}$ \\
\hline 10 & & & $98 / 5$ & 202-204 & $205-20754$ \\
\hline 11 & & & $97 / 5$ & 229-232 & $227-230^{60}$ \\
\hline 12 & & & $94 / 10$ & $211-214$ & $212-215^{54}$ \\
\hline 13 & & & $95 / 10$ & 200-202 & $201-203^{54}$ \\
\hline & & $6 \mathrm{~m}$ & & & \\
\hline
\end{tabular}


with both electron-withdrawing and electrondonating substituents were explored and the results of their reaction with 3-methyl-1phenyl-1H-pyrazol-5(4H)-one and malononitrile (or ethyl cyanoacetate) were summarized in Table 2. Aromatic aldehydes with both electronwithdrawing and electron-donating groups underwent smooth transformation to the corresponding pyrano[2,3-c]pyrazole derivatives, with no side products formation at high-toexcellent yields and in short reaction times.

The catalytic activity of SCMNPs@PC/VB 1 $\mathrm{Zn}$ was investigated for the synthesis of $4 \mathrm{H}$ benzo-[b]-pyran derivatives via one-pot threecomponent reactions of dimedone, aldehydes, and malononitrile. To optimize the reaction conditions, we investigated the condensation among dimedone, 4-chlorobenzaldehyde, and

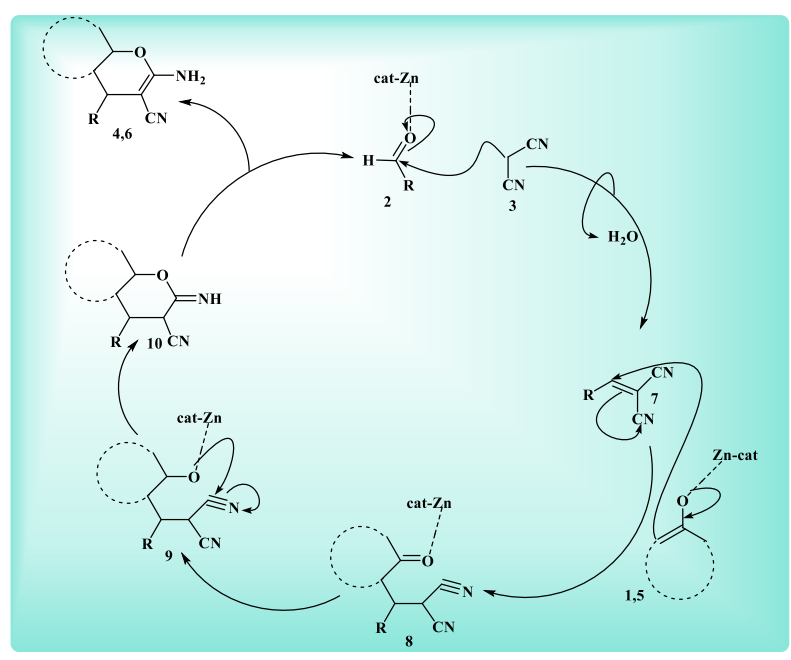

Scheme 3. A plausible mechanism for the onepot three-component reaction of 3-methyl-1phenyl-1H-pyrazol-5(4H)-one $1 /$ dimedone 5 , aldehyde 2 , and malononitrile 3 , catalyzed by SCMNPs@PC/VB 1 -Zn under solvent-free conditions. malononitrile as a model reaction in the presence of various conditions (Table 3). In the best reaction condition, we used $10 \mathrm{mg}$ of the SCMNPs@PC/VB 1 -Zn for $1 \mathrm{mmol}$ of any substrates at $50^{\circ} \mathrm{C}$ under solvent-free conditions (Table 3, Entry 4). Moreover, in order to compare the efficiency of this prepared catalyst with that of some previously reported catalysts for the synthesis of $4 H$-benzo-[b]-pyran derivatives ( see Table 3, Entries 12-16), we bring the results for these catalysts in the synthesis of $6 \mathrm{~d}$ as a model reaction.

After optimizing the conditions, the efficiency and versatility of the SCMNPs@PC/VB $1-\mathrm{Zn}$ as a catalyst for the preparation of $4 \mathrm{H}$-benzo[b]-pyran derivatives were evaluated by different aromatic aldehydes with both electronwithdrawing and electron-donating substituents. In all the studied cases, the reaction proceeded smoothly to give the desired products 6a-m (Table 4).

Scheme 3 illustrates a mechanism proposed for one-pot three-component condensation of 3methyl-1-phenyl-1 $H$-pyrazol-5(4H)-one $1 / \mathrm{dim}$ edone 5 , aldehyde 2 , and malononitrile 3 in the presence of SCMNPs@PC/VB 1 -Zn. Initially, the Knoevenagel condensation of aromatic aldehyde and malononitrile in the presence of SCMNPs@PC/VB 1 -Zn formed alkylidene malononitrile as an intermediate (7). After that, in the presence of SCMNPs@PC/VB $1-\mathrm{Zn}$, Michael addition reaction between $\mathrm{C}-\mathrm{H}$-activated acids 1 and 5 and alkylidene malononitrile 7 , intramolecular cyclization $(8,9)$, and aromatization (10), lead to desired products 4 and 6 .

The reusability of the SCMNPs@PC/VB $1-\mathrm{Zn}$ was studied for the reaction between 3-methyl1-phenyl-1H-pyrazol-5(4H)-one/dimedone, benzaldehyde, and malononitrile under solventfree conditions. The catalyst was recovered by an external magnetic field and washed with


Figure 8. The recycling of SCMNPs@PC/VB $1-\mathrm{Zn}$ in the preparation of pyrano[2,3-c]pyrazole (a) and $4 H$-benzo-[b]-pyran (b) derivatives. 
ethanol. After that, SCMNPs@PC/VB 1 -Zn was dried and reused over 6 runs with some decrease in the catalytic activity (Figure 8).

\section{Conclusion}

A simple method for the immobilization of $\mathrm{Fe}_{3} \mathrm{O}_{4}$ MNPs by functional groups was introduced via the reaction of $\mathrm{OH}$ groups on $\mathrm{Fe}_{3} \mathrm{O}_{4}$ level. Innovative SCMNPs@PC/VB $1-\mathrm{Zn}$ has been utilized as an effective and reusable catalyst for one-pot synthesis of pyrano[2,3c]pyrazoles and 1,8-dioxooctahydroxanthene derivatives. Serious analyses, such as: FTIR, XRD, VSM, EDX, TGA, and SEM, investigated the structure of the synthesized catalysts. The significant advantages of our protocol include high-to-excellent yields, short reaction time, simple separation and reusability of the catalyst.

\section{References}

[1] Utkan, G.G., Sayar, F., Batat, P., Ide, S., Kriechbaum, M., Pişkin, E. (2011). Synthesis and characterization of nanomagnetite particles and their polymer coated forms. Journal of colloid and interface science, 353(2), 372379 .

[2] Park, J., An, K., Hwang, Y., Park, J.G., Noh, H.J., Kim, J.Y., Park, J.H., Hwang, N.M., Hyeon, T. (2004). Ultra-large-scale syntheses of monodisperse nanocrystals. Nature materials, 3(12), 891-895.

[3] Mizutani, N., Iwasaki, T., Watano, S., Yanagida, T., Tanaka, H., Kawai, T. (2008). Effect of ferrous/ferric ions molar ratio on reaction mechanism for hydrothermal synthesis of magnetite nanoparticles. Bulletin of Materials Science, 31(5), 713-717.

[4] Morel, A.L., Nikitenko, S.I., Gionnet, K., Wattiaux, A., Lai-Kee-Him, J., Labrugere, C., Chevalier, B., Deleris, G., Petibois, C., Brisson, A., Simonoff, M. (2008). Sonochemical approach to the synthesis of $\mathrm{Fe}_{3} \mathrm{O}_{4} @ \mathrm{SiO}_{2}$ coreshell nanoparticles with tunable properties. ACS Nano, 2(5), 847-856.

[5] Panella, B., Vargas, A., Baiker, A. (2009). Magnetically separable Pt catalyst for asymmetric hydrogenation. Journal of Catalysis, 261(1), 88-93.

[6] Wei, Y., Han, B., Hu, X., Lin, Y., Wang, X., Deng, X. (2012). Synthesis of $\mathrm{Fe}_{3} \mathrm{O}_{4}$ nanoparticles and their magnetic properties. Procedia Engineering, 27, 632-637.

[7] Shiri, L., Ghorbani-Choghamarani, A., Kazemi, M. (2016). Sulfides synthesis: nanocatalysts in $\mathrm{C}-\mathrm{S}$ cross-coupling reactions.
Australian Journal of Chemistry, 69(6), 585600.

[8] Kim, Y.S., Kim, Y.H. (2003). Application of ferro-cobalt magnetic fluid for oil sealing. Journal of Magnetism and Magnetic Materials, 267(1), 105-110.

[9] Ghorbani-Choghamarani, A., Norouzi, M. (2014). Synthesis of copper (II)-supported magnetic nanoparticle and study of its catalytic activity for the synthesis of 2,3dihydroquinazolin-4(1H)-ones. Journal of Molecular Catalysis A: Chemical, 395, 172-179.

[10] Hoener, C.F., Allan, K.A., Bard, A.J., Campion, A., Fox, M.A., Mallouk, T.E., Webber, S.E., White, J.M. (1992). Demonstration of a shell-core structure in layered cadmium selenide-zinc selenide small particles by $\mathrm{x}$-ray photoelectron and Auger spectroscopies. The Journal of Physical Chemistry, 96(9), 38123817.

[11] Yao, G.H., Wang, F., Wang, X.B., Gui, K.T. (2010). Magnetic field effects on selective catalytic reduction of $\mathrm{NO}$ by $\mathrm{NH}_{3}$ over $\mathrm{Fe}_{2} \mathrm{O}_{3}$ catalyst in a magnetically fluidized bed. Energy, 35(5), 2295-2300.

[12] Ishii, M., Nakahira, M., Yamanaka, T. (1972). Infrared absorption spectra and cation distributions in (Mn, $\mathrm{Fe})_{3} \mathrm{O}_{4}$. Solid State Communications, 11(1), 209-212.

[13] Tartaj, P., Morales, M.P., Gonzalez-Carreño, T., Veintemillas-Verdaguer, S., Serna, C.J. (2011). The Iron Oxides Strike Back: From Biomedical Applications to Energy Storage Devices and Photoelectrochemical Water Splitting. Advanced Materials, 23, 5243-5249.

[14] Laurent, S., Forge, D., Port, M., Roch, A., Robic, C., Vander Elst, L., Muller, R.N. (2008). Magnetic iron oxide nanoparticles: synthesis, stabilization, vectorization, physicochemical characterizations, and biological applications. Chemical reviews, 108(6), 2064-2110.

[15] Sharma, P., Rana, S., Barick, K.C., Kumar, C., Salunke, H.G., Hassan, P.A. (2014). Biocompatible phosphate anchored $\mathrm{Fe}_{3} \mathrm{O}_{4}$ nanocarriers for drug delivery and hyperthermia. New Journal of Chemistry, 38(11), 55005508.

[16] Huh, Y.M., Jun, Y.W., Song, H.T., Kim, S., Choi, J.S., Lee, J.H., Yoon, S., Kim, K.S., Shin, J.S., Suh, J.S., Cheon, J. (2005). In vivo magnetic resonance detection of cancer by using multifunctional magnetic nanocrystals. Journal of the American Chemical Society, 127(35), 12387-12391.

[17] Jordan, A., Scholz, R., Wust, P., Fähling, H., Felix, R. (1999). Magnetic fluid hyperthermia (MFH): Cancer treatment with AC magnetic 
field induced excitation of biocompatible superparamagnetic nanoparticles. Journal of Magnetism and Magnetic materials, 201(1-3), 413-419.

[18] Aghbash, K.O., Pesyan, N.N., Batmani, H. (2019). $\quad \mathrm{Fe}_{3} \mathrm{O}_{4} @$ silica-MCM-41@DABCO: A novel magnetically reusable nanostructured catalyst for clean in situ synthesis of substituted 2-aminodihydropyrano [3,2-b] pyran-3-cyano. Applied Organometallic Chemistry. 33 (11) e5227.

[19] Yahyazadeh, A., Abbaspour-Gilandeh, E., Aghaei-Hashjin, M. (2018). Four-Component Synthesis of 2-Amino-3-Cyanopyridine Derivatives Catalyzed by $\mathrm{Cu} @$ imineZCMNPs as a Novel, Efficient and Simple Nanocatalyst Under Solvent-Free Conditions. Catalysis Letters, 148(4), 1254-1262.

[20] Abbaspour-Gilandeh, E., Yahyazadeh, A., Aghaei-Hashjin, M. (2018). One-pot synthesis of 3,4-dihydropyrimidin-2 $(1 \mathrm{H})$-ones catalyzed by $\mathrm{SO}_{3} \mathrm{H} @$ imineZCMNPs as a novel, efficient and reusable acidic nanocatalyst under solvent-free conditions. RSC advances, 8(70), 40243-40251.

[21] Torabi, M., Yarie, M., Zolfigol, M.A. (2019). Synthesis of a novel and reusable biological urea based acidic nanomagnetic catalyst: Application for the synthesis of 2-amino-3-cyano pyridines via cooperative vinylogous anomeric based oxidation. Applied Organometallic Chemistry, 33(6), e4933.

[22] Foloppe, N., Fisher, L.M., Howes, R., Potter, A., Robertson, A.G., Surgenor, A.E. (2006). Identification of chemically diverse Chk1 inhibitors by receptor-based virtual screening. Bioorganic \& medicinal chemistry, 14(14), 4792-4802.

[23] Smith, P.W., Sollis, S.L., Howes, P.D., Cherry, P.C., Starkey, I.D., Cobley, K.N., Weston, H., Scicinski, J., Merritt, A., Whittington, A., Wyatt, P. (1998). Dihydropyrancarboxamides related to zanamivir: A new series of inhibitors of influenza virus sialidases. 1. Discovery, synthesis, biological activity, and structureactivity relationships of 4-guanidino-and 4amino-4 H-pyran-6-carboxamides. Journal of Medicinal Chemistry, 41(6), 787-797.

[24] Zaki, M.E., Soliman, H.A., Hiekal, O.A., Rashad, A.E. (2006). Pyrazolopyranopyrimidines as a class of anti-inflammatory agents. Zeitschrift für Naturforschung C, 61(1-2), 1-5.

[25] Zaki, M.E., Morsy, E.M., Abdel-Motti, F.M., \& Abdel-Megeid, F.M.E. (2004). The behaviour of ethyl 1-acetyl-4-aryl-5-cyano-3-methyI-1, 4dihydropyrano [2,3-c] pyrazol-6ylimidoformate towards nucleophiles. Heterocyclic Communications, 10(1), 97-102.
[26] Ren, Z., Cao, W., Tong, W., Jin, Z. (2005). Solvent-free, one-pot synthesis of pyrano [2,3-c] pyrazole derivatives in the presence of $\mathrm{KF} .2 \mathrm{H}_{2} \mathrm{O}$ by grinding. Synthetic Communications, 35(19), 2509-2513.

[27] Abdollahi-Alibeik, M., Moaddeli, A., Masoomi, K. (2015). $\mathrm{BF}_{3}$ bonded nano $\mathrm{Fe}_{3} \mathrm{O}_{4}$ $\left(\mathrm{BF}_{3} / \mathrm{MNPs}\right)$ : an efficient magnetically recyclable catalyst for the synthesis of 1, 4dihydropyrano [2,3-c] pyrazole derivatives. RSC Advances, 5(91), 74932-74939.

[28] Jin, T.S., Zhao, R.Q., Li, T.S. (2006). An onepot three-component process for the synthesis of 6-amino-4-aryl-5-cyano-3-methyl-1-phenyl1,4- dihydropyrano[2,3-c]pyrazoles in aqueous media. Arkivoc, xi, 176-182.

[29] Heravi, M.M., Ghods, A., Derikvand, F., Bakhtiari, K., Bamoharram, F.F. (2010). $\mathrm{H}_{14}\left[\mathrm{NaP}_{5} \mathrm{~W}_{30} \mathrm{O}_{110}\right]$ catalyzed one-pot threecomponent synthesis of dihydropyrano [2, 3-c] pyrazole and pyrano [2, 3-d] pyrimidine derivatives. Journal of the Iranian Chemical Society, 7(3), 615-620.

[30] Shi, D., Mou, J., Zhuang, Q., Niu, L., Wu, N., Wang, X. (2004). Three-component one-pot synthesis of 1,4-dihydropyrano [2,3-c] pyrazole derivatives in aqueous media. Synthetic communications, 34(24), 4557-4563.

[31] Sheibani, H., Babaie, M. (2009). Threecomponent reaction to form 1,4dihydropyrano [2,3-c] pyrazol-5-yl cyanides. Synthetic Communications, 40(2), 257-265.

[32] Jin, T.S., Wang, A.Q., Cheng, Z.L., Zhang, J.S., Li, T.S. (2005). A clean and simple synthesis of 6 -amino-4-aryl-5-cyano-3-methyl-1phenyl-1, 4-dihydropyrano [2,3-c] pyrazole in water. Synthetic communications, 35(1), 137 143.

[33] Rostami, A., Atashkar, B., Gholami, H. (2013). Novel magnetic nanoparticles $\mathrm{Fe}_{3} \mathrm{O}_{4}$ immobilized domino Knoevenagel condensation, Michael addition, and cyclization catalyst. Catalysis Communications, 37, 69-74.

[34] Mogilaiah, K., Chandra, A.V., Srivani, N., Kumar, K.S. (2013). Convenient synthesis of 5-oxo-5, 6,7,8-tetrahydro-4H-1-benzopyrans using $\mathrm{LiCl} / \mathrm{Al}_{2} \mathrm{O}_{3}$ under microwave irradiation. Indian Journal of Chemistry-Section B, 52B(02), 306-308.

[35] Ranu, B.C., Banerjee, S., Roy, S. (2008). A task specific basic ionic liquid,[bmIm] $\mathrm{OH}$ promoted efficient, green and one-pot synthesis of tetrahydrobenzo [b] pyran derivatives. Indian Journal of Chemistry, 47 (1108-1112).

[36] Liqin, Z., Yiqun, L., Lu, C., \& Bo, Z. (2010). One-pot synthesis of tetrahydrobenzo [b] pyran catalyzed by basic quaternary ammonium salt in aqueous medium. Chinese Journal of Organic Chemistry, 30(1), 124-127. 
[37] Khaksar, S., Rouhollahpour, A., Talesh, S.M. (2012). A facile and efficient synthesis of 2amino-3-cyano-4H-chromenes and tetrahydrobenzo [b] pyrans using 2,2,2-trifluoroethanol as a metal-free and reusable medium. Journal of Fluorine Chemistry, 141, 11-15.

[38] Zeng, Z.G., Wang, L.Y., Cao, Y., Luo, Y.P. (2012). Synthesis of 2-amide-3-carboxylate-4aryl-4H-chromene derivatives. Research on Chemical Intermediates, 38(8), 1751-1760.

[39] Li, J.T., Xu, W.Z., Yang, L.C., Li, T.S. (2004). One-Pot Synthesis of 2-Amino-4-aryl-3carbalkoxy-7, 7-dimethyl-5,6,7, 8tetrahydrobenzo [b] pyran Derivatives Catalyzed by $\mathrm{KF} / \mathrm{Basic} \mathrm{Al}_{2} \mathrm{O}_{3}$ Under Ultrasound Irradiation. Synthetic communications, 34(24), 4565-4571.

[40] Hasaninejad, A., Jafarpour, N., Mohammadnejad, M. (2012). Synthesis of benzo [b] pyrane derivatives using supported potassium fluoride as an efficient and reusable catalytic system. Journal of Chemistry, 9(4), 20002005.

[41] Wang, L.M., Shao, J.H., Tian, H., Wang, Y.H., Liu, B. (2006). Rare earth perfluorooctanoate $\left[\mathrm{RE}(\mathrm{PFO})_{3}\right]$ catalyzed one-pot synthesis of benzopyran derivatives. Journal of fluorine chemistry, 127(1), 97-100.

[42] Khodaei, M.M., Bahrami, K., Farrokhi, A. (2010). Amberlite IRA-400 (OH-) as a Catalyst in the Preparation of $4 \mathrm{H}$-Benzo [b] pyrans in Aqueous Media. Synthetic Communications, 40(10), 1492-1499.

[43] Ponpandian, T., Muthusubramanian, S. (2014). One-pot, catalyst-free synthesis of spirooxindole and $4 \mathrm{~h}$-pyran derivatives. Synthetic Communications, 44(6), 868-874.

[44] Tahmassebi, D., Bryson, J.A., Binz, S.I. (2011). 1,4-Diazabicyclo [2.2.2] octane as an efficient catalyst for a clean, one-pot synthesis of tetrahydrobenzo [b] pyran derivatives via multicomponent reaction in aqueous media. Synthetic Communications, 41(18), 27012711.

[45] Brahmachari, G., Banerjee, B. (2013). Facile and one-pot access to diverse and densely functionalized 2-amino-3-cyano-4 H-pyrans and pyran-annulated heterocyclic scaffolds via an eco-friendly multicomponent reaction at room temperature using urea as a novel organo-catalyst. ACS Sustainable Chemistry \& Engineering, 2(3), 411-422.

[46] Elnagdi, N.M.H., Al-Hokbany, N.S. (2012). Organocatalysis in synthesis: L-proline as an enantioselective catalyst in the synthesis of pyrans and thiopyrans. Molecules, 17(4), 4300-4312.
[47] Jin, T.S., Wang, A.Q., Shi, F., Han, L.S., Liu, L.B., Li, T.S. (2006). Hexadecyldimethyl benzyl ammonium bromide: an efficient catalystfor a clean one-pot synthesis of tetrahydrobenzopyran derivatives in water. Arkivoc, $14,78-86$.

[48] Pore, D.M., Undale, K.A., Dongare, B.B., Desai, U.V. (2009). Potassium phosphate catalyzed a rapid three-component synthesis of tetrahydrobenzo [b] pyran at ambient temperature. Catalysis letters, 132(1-2), 104-108.

[49] Gao, S., Tsai, C.H., Tseng, C., Yao, C.F. (2008). Fluoride ion catalyzed multicomponent reactions for efficient synthesis of $4 \mathrm{H}$ chromene and $\mathrm{N}$-arylquinoline derivatives in aqueous media. Tetrahedron, 64(38), 91439149.

[50] Bhosale, R.S., Magar, C.V., Solanke, K.S., Mane, S.B., Choudhary, S.S., Pawar, R.P. (2007). Molecular iodine: An efficient catalyst for the synthesis of tetrahydrobenzo [b] pyrans. Synthetic Communications, 37(24), 4353-4357.

[51] Maleki, B., Ashrafi, S.S. (2014). Nano $\alpha-\mathrm{Al}_{2} \mathrm{O}_{3}$ supported ammonium dihydrogen phosphate $\left(\mathrm{NH}_{4} \mathrm{H}_{2} \mathrm{PO}_{4} / \mathrm{Al}_{2} \mathrm{O}_{3}\right)$ : preparation, characterization and its application as a novel and heterogeneous catalyst for the one-pot synthesis of tetrahydrobenzo [b] pyran and pyrano [2, 3-c] pyrazole derivatives. RSC Advances, 4(81), 42873-42891.

[52] Shinde, S.V., Jadhav, W.N., Kondre, J.M., Gampawar, S.V., Karade, N.N. (2008). Sulfamic acid catalysed one-pot three-component condensation for the synthesis of 1, 4dihydropyrano [2, 3-c] pyrazoles. Journal of Chemical Research, 2008(5), 278-279.

[53] Farahi, M., Karami, B., Sedighimehr, I., \& Tanuraghaj, H. M. (2014). An environmentally friendly synthesis of 1, 4-dihydropyrano [2, 3-c] pyrazole derivatives catalyzed by tungstate sulfuric acid. Chinese Chemical Letters, 25(12), 1580-1582.

[54] Mobinikhaledi, A., Fard, M.A.B. (2010). Tetrabutylammonium bromide in water as a green media for the synthesis of pyrano [2, 3d] pyrimidinone and tetrahydrobenzo [b] pyran derivatives. Acta Chimica Slovenica, 57(4), 931-935.

[55] Wang, L.M., Shao, J.H., Tian, H., Wang, Y.H., Liu, B. (2006). Rare earth perfluorooctanoate $\left[\mathrm{RE}(\mathrm{PFO})_{3}\right]$ catalyzed one-pot synthesis of benzopyran derivatives. Journal of fluorine chemistry, 127(1), 97-100.

[56] Tu, S., Wang, H., Feng, J., Tang, A., \& Feng, J. (2001). A Convenient Synthesis of 2Amino-5,6,7,8-Tetrahydro-5-Oxo-4-Aryl-7,7Dimethyl-4H-Benzo-[B]-Pyran-3-Ethylcarboxylates under Microwave Irradiation. 
Synthetic Communications, 31(17), 26632666.

[57] Hekmatshoar, R., Majedi, S., Bakhtiari, K. (2008). Sodium selenate catalyzed simple and efficient synthesis of tetrahydro benzo [b] pyran derivatives. Catalysis Communications, 9(2), 307-310.

[58] Joshi, V.M., Magar, R.L., Throat, P.B., Tekale, S.U., Patil, B.R., Kale, M.P., Pawar, R.P. (2014). Novel one-pot synthesis of $4 \mathrm{H}$ chromene derivatives using amino functionalized silica gel catalyst. Chinese Chemical Letters, 25(3), 455-458.
[59] Nemouchi, S., Boulcina, R., Carboni, B., Debache, A. (2012). Phenylboronic acid as an efficient and convenient catalyst for a threecomponent synthesis of tetrahydrobenzo[b] pyrans. Comptes Rendus Chimie, 15(5), 394397.

[60] Balalaie, S., Bararjanian, M., SheikhAhmadi, M., Hekmat, S., Salehi, P. (2007). Diammonium hydrogen phosphate: An efficient and versatile catalyst for the one-pot synthesis of tetrahydrobenzo [b] pyran derivatives in aqueous media. Synthetic Communications, 37(7), 1097-1108. 